\title{
Predictors for time to recovery from sever acute malnutrition among under-five children admitted to therapeutic feeding unit at Dubti referral hospital, Afar region, Ethiopia
}

\author{
Awoke Seyoum Tegegne* and Denekew Bitew Belay
}

\begin{abstract}
Background: Currently, about 165 million children are categorized under malnutrition and 51.5 million suffering from acute malnutrition in world wide. Hence, the objective of current study was to assess the recovery time and its predictors of children under five from severe acute malnutrition admitted to Therapeutic Feeding Unit at Dubti Referral Hospital, Afar region, Eastern Ethiopia.
\end{abstract}

Methods: Institutional based retrospective cohort study was conducted on 650 inpatient children with SAM admitted for therapeutic feeding unit whose treatment was from March to April/2017.

Results: The result in current investigation indicates that the average recovery time from SAM was found to be 21 days (95\% Cl; 21.23-25.77), $p$-value $=0.035)$. A Cox proportional hazard regression model revealed that Weight of a child at birth, gestational age of a child, working status of a child at admission birth order of a child, mother's BMI, mother's level of education, mother's stature, mother's occupation, mother's age, mother's marital status, mother's nutritional status, house hold income in ETB, family size in $\mathrm{HH}$, number of under-five children, the type of toilet used in $\mathrm{HH}$, source of improved drinking water, type of cooking fuel, ownership of livestock, age and weight of a child at admission had statistically significant association with the variation of average recovery time of children from SAM.

Conclusion: Male children under severe acute malnutrition, rural children, children with different additional diseases and children who did not get mothers' breast milk at least in the first six months after birth and children who did not get vaccination are groups at risk and needs intervention and special attention to be recovered with short period of time. Children from low income family, who did not get improved drinking water, without moderate cooking fuel and a child from larger families were groups at risk in recovery time from SAM.

Keywords: SAM, Average recovery time, Acute malnutrition, Global malnutrition, Recovery rate

\section{Background}

Currently, an estimated number of 165 million children are categorized under malnutrition (stunting, wasting and underweight) and 51.5 million suffering from acute malnutrition in world wide. The hazard leads to

*Correspondence: bisrategebrail@yahoo.com

Department of Statistics, Bahir Dar University, Bahir Dar, Ethiopia morbidity and mortality of childhood because of malnutrition and this further leads to worse in children intellectual growth, adult efficiency and may rise in the hazard of enlargement for a firm of disease in parenthood [1]. Acute malnutrition attributes to 875,000 deaths of under five children and this accounts for $12.6 \%$ of all deaths in under five children [2]. 
Enlightening of diet is a worldwide primacy, with the aim of reducing global malnutrition by 2030 that had been incorporated in the 2015 United Nations Sustainable Development Goals [2, 3]. Malnutrition in children remains main community well-being risk in several low income nations especially, Sub-Saharan Africa and it remains to be the supreme essential determinant factor for physical and mental growth obstacle, progression of disease and finally large mass of deaths in young children [4]. Malnutrition consists of Severe, Chronic or Sever Acute Malnutrition (SAM).

Malnutrition is said to be Sever Acute Malnutrition(SAM), if body mass index is less than 3 standard deviation or weight for height ratio is less than $70 \%$ [5]. Among children suffering from SAM, the widespread are found in Southern and Southeast Asia and Sub-Saharan Africa [6]. In countries like India, Indonesia, Kenya and Ethiopia, SAM not only exist in sudden situations, but also it is existed in stable settings [7]. In these countries, SAM is perceived as a condition of community-spirited disasters rather than progressive and health importance [8]. The risk of SAM further leads to longterm economic and social burden in such countries [9].

The reason for this, may be owed to limitation of the wellbeing conditions and occurrence of bottle neck obstacles at lower levels of healthcare surroundings [10]. This might be due to limitation of health care settings and occurrence of different challenges at local levels of low resource healthcare surroundings [11].

Ethiopia is one of the Sub-Saharans Africa in which many children are suffering from SAM and all activities with treatment outcomes of SAM in the healthcare surroundings could be assessed. Few studies had been conducted in Ethiopia about SAM and as far as the investigators knowledge is concerned, there is a scarce of studies about predictors of children's survival time from SAM, admitted to therapeutic feeding unit in the study area.

Because of its cost effectiveness, an integrated communal based control of SAM is currently well-thought-out as standard for care of basic SAM [12]. A research investigated on control of clinical and public trials in Ethiopia approved that community based management program should be conducted in large-scale implementation by government's health institutions [11].

Previous research conducted on outpatient therapeutic feeding unit program in southern Ethiopia, revealed that there is a great challenge in conducting an integrated communal based program for SAM, especially remotest areas in the country [13]. The previous investigation also revealed that, only $39 \%$ of an Integrated Community based Outpatient Therapeutic program (ICOTP) fulfill the local and World Health
Organization (WHO) guideline. The previous study also revealed that, recovery of children from SAM based on WHO guidelines using outpatient therapeutic feeding unit is not an easy task to be practically implemented [10, 13].

Another study highlighted about the challenges of scaling up of ICOTP in to the lowest levels of the health institutions and needs for an investigation of the recovery time of children enrolled for SAM based on the national and WHO recovery guideline [14]. Another investigation conducted in Ethiopia, stated that, household level treatment for SAM is no longer effective and for the program to be successful. On the other hand, access to potentially life-saving care for every child enrolled at health facilities using an integrated Mid-Upper Arm-Circumference (MUAC) in primary health care surroundings is recommended to be conducted [15]. Most of the previous researches focused on the experience and challenges of applying WHO's guideline and did not investigate sociodemographic and economic factors affecting recovery time of children from SAM.

The objective of current investigation was therefore, to assess recovery time from SAM and its determinant factors amongst children under five admitted to therapeutic feeding unit at Dubti Referral Hospital, Afar region, Eastern part of Ethiopia. The treatment site in the country is known by its shortage of food for community.

\section{Methods}

\section{Setting and study design}

The study was conducted using institutional based retrospective cohort data recorded from March to April, 2017 at Dubti Referral Hospital in Afar region, Eastern Ethiopia. The hospital provides inpatient services for primary health care for children with SAM in the region. The study employed secondary data collected by health staffs.

Source of data The data from the chart of each child was collected by the health staff to assess the visibility of primary health care surroundings. Hence, current study used secondary data collected from health institution (Dupti Referal Hospital).

Data collection procedures During data collection, health staffs and clinical nurses were participated in collecting secondary data from cards of patients and a public health expert was assign as a supervisor and orientation was given for data collectors about the variables under current investigation. The data collection format was developed by the investigators in consultation with the health staff, considering the national and WHO protocol for the management of SAM. 


\section{Eligibility criteria}

All children under five with SAM that have been admitted as inpatient for primary health care and treated at therapeutic feeding unit (TFU) in Dupti referral hospital from March to April, 2017 were eligible for the study. The study included children who got treatment for SAM, children admitted for MUAC value of B110 $\mathrm{mm}$ or bilateral pitting nutritional edema, children who tested their appetite and passed the test and children without treatment difficulties in the hospital were included in current investigation. Study participants were categorized as Marasmus (children with nutritional edema) and kwashiorkor (children without nutritional edema).

Sample size and sampling procedure To compute an appropriate sample size, an Open Epi version 2.3 was used with the assumption that the proportion was recovered in both Marasmus and Kwashiorkor group children at 95\% CI and 5\% marginal error. Using this approach, the smallest size for both groups was 590 . To compensate for potential losses of information for missingness, $10 \%$ of the sample was added. Hence, about 650 children who got treatment in the hospital were taken as a sample in both groups (Marasmus and Kwashiorkor).

From the selected hospital, eligible children with SAM were identified using patients' card and list of individual in sample selection procedure was developed as sampling frame. Proportional allocation was employed for groups namely Marasmus and Kwashiorkor groups. Finally, individual participants were selected using systematic random sampling using patients' card number.

Data cleaning and checking its quality Both the data collectors and the supervisors got two days training/orientation about the variables under current investigation. There was a close follow ups or supervisions of the data collection by public health experts. After data collection, data were entered in to Epi info version 6 by data encoders and cleaned all the errors created during data entry. This was done by the investigators with one health staff (to check the appropriate use of medical terminologies under this investigation). Hence, Data were cleaned before data analysis and close follow ups were there in collecting secondary data. Pilate test was conducted to test the relevancy and quality of instruments used for data collection. The completeness and consistency of questions in this regard was also checked on 45 sample data and proper amendments were included after getting feedbacks from pilot test.

\section{Study variables}

Response variable The response variable for current investigation was average recovery time from Severe Acute Malnutrition (SAM). Malnutrition consists of stunting, wasting and under-weight.

Predictor variables The predictor variables consists of breast feeding history (yes, no), weight of a child at birth, gestational age of a child (extremely preterm (less than 28 weeks), very preterm (between 28 and 32 weeks, late preterm (between 32 and 37 weeks), working status of a child(yes, no), birth order of a child (first, 2-4, $>4$ ), parent's level of education(no-education, primary, secondary and above), mother's stature(normal, short), mother's occupation (household wife, Gov't employee, Private), mother's age categories(15-24, 25-34, 35-44, $>45$ ), mother's marital status(married, others), house hold income in $\operatorname{ETB}(<500,500-1000,>1000)$, age ranges between children $(<2$ years, $>=2$ years $)$, family size in $\mathrm{HH}(<5,5-10,>10)$, number of under-five children $(<2$, $>=2$ ), Source of improved drinking water(yes, no), type of cooking fuel(moderate, traditional), adequate access of $\mathrm{HH}$ food (yes, no), sex of a child (male, female), Residence area(rural, urban), malnutrition type (stunted, wasted, under-weight), age in months and weight in $\mathrm{kg}$, type of house families live(moderate, traditional).

Measurements of time variant and in-variant covariates MUAC was measured on the left upper arm of a child with the arm hanging down of the body and. The value obtained in this way was recorded to the nearest value of $1 \mathrm{~mm}$. First, desire for food on outpatient children was tested weekly for children enrolled in the program. A child was said to pass the desire for food test, if she or he was able to eat the food ready to use therapeutic food (RUTF) recommended for her or his body weight. On the other hand, children who failed the appetite test conducted weekly were referred to inpatient care [16]. Depending on their weight, the national protocol for management of SAM directed children to receive different number of RUTF $[17,18]$. The progression of MUAC in $\mathrm{mm} /$ day and weight increase in $\mathrm{g} / \mathrm{kg} /$ day was computed for all inpatient children enrolled for SAM in the hospital.

The nutritional status of children was also assessed and categorized as malnutrition or not. Malnutrition consists of Severe, Chronic or Sever Acute Malnutrition (SAM). Malnutrition is said to be Sever Acute Malnutrition(SAM), if body mass index was less than 3 standard deviation or weight for height ratio is less than $70 \%[5]$. 
For children with kwashiorkor, the change of MUAC and the change in weight were computed after the edema has been determined. Children admitted for treatment was categorized as new (admitted for the first time or after 2 months of recovery) or re-admitted (admitted within two months of recovery). A child was considered as discharged from treatment because of his/her recovery from SAM, move/transfer to other health facilities, defaulted from treatment or death, Body weight was measured using a digital weighting scale and for children whose age was less than three months. Here, a $25-\mathrm{kg}$ hanging spring scale graduated by $0.1 \mathrm{~kg}$ was used.

Follow up characteristics of children with SAM related to lose of edema and weight gain in the first phase was conducted on this cohort on the 4th, 10th day and day 10 was considered as cut of point to pass to the second phase. A child was recovered from SAM if he/she obtained 15\% of weight expected (target weight) and become free from edema [19].

Admission medication In the admission procedure, amoxicillin was given for one week. At a time admission, vitamin A was given for all children. Vitamin A was also given for children at the fourth visit, if they become free from edema and for those children who did not take it for the last 6 months after birth [20], Measles vaccine was given on the fourth visit, and Deworming was given on the second visit [19].

\section{Data processing and analysis}

Data were entered in to Epi info version 6 statistical software and then exported to SPSS version 23 for analysis. Data was described using percentages for qualitative data and averages for continuous variables. To test the association between categorical variables, Pearson chi-square test was used.

\section{Statistical models used for current investigation}

Kaplan Meier estimator which is a non-parametric survival curve was applied in this invesitigation [20]. If $n$ subjects are on test and ordered the observed lifetimes for these $n$ individuals from $t_{(1)}$ to $t_{(n)}$ and $r$ individaules are cured, then ordered cure times are $t(1), \ldots, t(r)$, where $\mathrm{r} \leq \mathrm{n}$. The probability that an individual cures during the small time interval is estimated by $\frac{c_{j}}{n_{j}}$, where $c_{j}$ is censored time. The chanace of surviving through the interval from $\mathrm{t}_{(\mathrm{k})}$ to $\mathrm{t}_{(\mathrm{k}+1)}$, and all preceding intervals lead to the Kaplan-Meier estimate of the survival function, which is given by:

$$
\hat{S}_{(t)}=\prod_{j=1}^{k} \frac{n_{j}-c_{j}}{n_{j}}
$$

The log rank test was used to compare two or more independent survival curves and usefull for non-overlapping survival curves. The log rank test statistic for comparing two groups is given by:

$$
X_{L R}=\frac{\left(\sum_{i=1}^{m} c_{1 i}-\sum_{i=1}^{m} \hat{e}_{1 i}\right)^{2}}{\sum_{i=1}^{m} \hat{v}\left(\hat{e}_{1 i}\right)}
$$

where $m$ is the number of rank ordered cures times, $c_{j i}$ is the number of people experiencing the event at time $t_{(i)}$ in group $j, n_{j i}$ is the number of people at risk in group $j$ at time $t_{(i)}, c_{i}$ is the total number experiencing the event in both groups, $\hat{e}_{j i}=\frac{c_{i} n_{j i}}{n_{i}}$ is the estimated expected number of individuals experiencing the event at $t_{(i)}$ in group $j$, $\hat{v}_{\left(\hat{e}_{j i}\right)}=\frac{n_{1 i} n_{2 i} c_{i}\left(n_{i}-c_{i}\right)}{n_{i}^{2}\left(n_{i}-1\right)}$ is the estimated variance of $\hat{e}_{j i}, n_{i}$ is the number of individuals at risk in both groups 1 and 2 just prior to event time $t_{(i)}$.

A Cox-proportional hazard model was also used for exploring the relationship between the survival time and several explanatory variables. The hazard function is proportional to the instantaneous risk at any time $t$, given that an individual has lived at least $\mathrm{t}_{0}$ up to time $\mathrm{t}$ and indicated by $\mathrm{h}(\mathrm{t})$ and is defined as follows [20]:

$$
\begin{gathered}
\mathrm{h}(\mathrm{t})=\lim _{\Delta \mathrm{t} \longrightarrow 0} \frac{\mathrm{P}[\mathrm{t} \leq \mathrm{T} \leq \mathrm{t}+\Delta \mathrm{t} \mid \mathrm{T} \geq \mathrm{t}]}{\Delta \mathrm{t}} \\
\mathrm{h}(\mathrm{t})=\mathrm{P}(\mathrm{t}<\mathrm{T}<(\mathrm{t}+\Delta \mathrm{t}) \mid \mathrm{T}>\mathrm{t}) \\
=\frac{\mathrm{f}(\mathrm{t})}{1-\mathrm{F}(\mathrm{t})}=\frac{\mathrm{f}(\mathrm{t})}{\mathrm{s}(\mathrm{t})}
\end{gathered}
$$

Since $h(t)$ is also equal to the negative of the derivative of $\ln (\mathrm{S}(\mathrm{t}))$, we have the useful identity:

$$
\mathrm{S}(\mathrm{t})=\mathrm{e}^{-\int_{0}^{\mathrm{t}} \mathrm{h}(\mathrm{t}) \mathrm{dt}}
$$

If we let $\mathrm{H}(\mathrm{t})=\int_{0}^{\mathrm{t}} \mathrm{h}(\mathrm{t}) \mathrm{dt}$ be the cdf (cumulative hazard function), we have $\mathrm{S}(\mathrm{t})=\mathrm{e}^{-\mathrm{H}(\mathrm{t})}$.

Then the general hazard regression model is:

$$
h(t, x)=h_{0}(t) \exp ^{(x \beta)}
$$

\section{Results}

Out of the total 650 children in the cohort; 384 (59.1\%) were males, most of study subjects $64.6 \%$ were rural residents. From all cohorts; $71.5 \%$ were newly admitted, $64.5 \%$ were edematous and $18.5 \%$ were wasted and the rest were both edematous and wasted. Among all children under malnutrition, 30\% didn't get their mothers' breast milk, the majority of them (64.6\%) were from rural area, $50.8 \%$ of them were at functional status, about $50.4 \%$ of the children were from the birth order of $2-4$, 
$70 \%$ of them had additional disease history. As, it is indicated in Tables $1,53 \%$ of the children were very preterm and $85.4 \%$ were born from short mothers, $68.8 \%$ of the children came from families in which their mother and father are not live together and $54.2 \%$ of them came from families with additional children with malnutrition (Ref. Table 1).

In the treatment site, admission medication was also conducted for all children and $19.2 \%$ of children received Amoxicillin, $14.8 \%$ of the children received Ampicillin and the majority of the children (44.5\%) received vitamin A.

Table 2 indicates that about half $(50.8 \%)$ of the children with SAM didn't start to reduce edema on the 4th day after getting treatment and $30.8 \%$ of the children with SAM had edema on the 10th day after getting treatment and $18.5 \%$ of children with SAM cannot pass to the second phase. Finally, about $38.5 \%$ of children with SAM didn't gain $>5$ g per day for three consecutive days.

At the end of study period, the discharged status for children with SAM was assessed and out of the total 650 children in the cohort, 408 (62.89\%) were recovered, 37 (5.7\%) died, 205 (31.5\%) defaulted, 9(1.4\%) not recorded on their card and $57(8.8 \%)$ transferred to other treatment sits. The nutritional recovery rate of this cohort was 3.56 per 100 -person. The average nutritional recovery time was estimated to be 21 days (95\% CI; (21.23-25.77).

In Table 3, it is indicated that the predictor variables and the variable of interest significantly associated each other with the value of chi-square and corresponding $p$-values. Hence, the chi-square and corresponding $\mathrm{p}$-values were evidence for the predictors and response variables to be highly associated.

The Kaplan-Meier survival curves for each study variable provide an initial insight for the shape of survival function. The Kaplan-Meier survival curves of three important covariates are indicated in Figs. 1, 2, 3.

Figure 1 indicates that those children who did not get immunization (immunization-status $=0$ ) had longer average recovery time from SAM as compared to those children who got immunization (immunization-status $=1$ ).

As it is indicated in Fig. 2, the average recovery time from SAM for children who did not get their mothers' breast milk (breast - feeding $=0$ ) was longer than those children who got mothers' breast milk (breast-feeding $=1$ ).

Figure 3 indicates that the average recovery time from SAM for those children who were con-infected with additional disease such as HIV, Diarrhoea, Vomiting, Cough, Fever $>39$ 'c, Anemia, Malaria, Pneumonia and TB $($ Co-infection $=1)$ was longer than those children free from such co-infected diseases (co-infection $=0)$. Hence, children with and without additional diseases had different average recovery time. The predictors of time to recovery from SAM in current investigation are indicated in Table 4.

As it is indicated in Table 4, the average recovery time from SAM for female children was decreased by $75 \%$ $(\mathrm{HR}=.25,95 \% \mathrm{CI}:(.11, .43)$, p-value $=0.002)$ as compared to male children and the average recovery time from SAM for urban children was decreased by $84 \%$ $(\mathrm{HR}=.16,95 \% \mathrm{CI}:(.13, .45), p$-value $=.025)$ as compared to children with vomiting. Similarly, the average recovery time from SAM for children with extremely preterm gestational age was increased by $35 \%(\mathrm{HR}=1.35$, $95 \%$ CI: $(1.06,1.67), p$-value $=0.01)$ as compared to late preterm children, keeping the other conditions constant. The average recovery time of working status children was decreased by $84 \%$ (HR $=.16,95 \%$ CI $(.12, .15)$, $p$-value $=0.021)$. The average recovery time of a child with normal mother's nutritional status was decreased by $42 \%(\mathrm{HR}=.52,95 \% \mathrm{CI}(.13, .85), p$-value $=.003)$. As age of a child increased by one month, the average recovery time of a child from SAM was decreased by $76 \%(\mathrm{HR}=.24,95 \% \mathrm{CI}$; $(.11, .34), p$-value $<.01)$ given the other covariates constant. Similarly, as weight of a child increased by one $\mathrm{kg}$, the average recory time of a child from SAM was decreased by $75 \%(\mathrm{HR}=.25,95 \% \mathrm{CI} ; . .11$, $.45), p$-value $=.002$ ).

Parents level of education had also significant effect for average recovery time of children from SAM. Hence, the average recovery time a child with non educated parent was increased by $92 \%(\mathrm{HR}=1.92,95 \% \mathrm{CI}$; $(1.52,4.58)$, $p$-value $=0.12)$ as compared to educated parents, keeping the other covariates constant. The average recovery time of a child whose house hold income greater than 1000 per month was decreased by $61 \%(\mathrm{HR}=.39,95 \%$ $\mathrm{CI}$; $(0.12,0.57), p$-value $=.01)$ as comapred to average recovery time of a child whose house hold income less 500 per moth. The average recovery time from SAM for a child who did not get adquate $\mathrm{HH}$ food was longer by $2 \%(\mathrm{HR}=1.02,95 \% \mathrm{CI} ;(1.01,1.32), p$-value $=0.013)$ as comapred to a child who got adquate $\mathrm{HH}$ food, keping the other things constant. The average recovery time from SAM for a child whose family had less than 2 under five chilred was shorter by $28 \%(\mathrm{HR}=.72,95 \% \mathrm{CI}$; $(.35$, $0.92), p$-value $=.002$ ).

The average recovery time from SAM for a child who did not get improved drinking water was longer by $4 \%(\mathrm{HR}=1.04,95 \% \mathrm{CI} ;(1.01,1.32), p$-value $=0.023)$ as comapred to a child who got improved drinking water, keping the other things constant. Similarly, the average recovery time from SAM for a child who did not get moderate cooking fuel was longer by $2 \%(\mathrm{HR}=1.02,95 \%$ CI; ((1.001, 1.081), $p$-value $=.021)$ as compared to those 
Table 1 Socio-demographic and baseline characteristics of study variables

\begin{tabular}{|c|c|c|c|}
\hline Variables & Category & Frequency & Percentage \\
\hline \multirow[t]{2}{*}{ Sex of a child } & Male & 384 & 59.1 \\
\hline & Female & 266 & 40.9 \\
\hline \multirow[t]{3}{*}{ Weight of a child at birth } & Small & 350 & 53.8 \\
\hline & Average & 220 & 33.8 \\
\hline & >average & 50 & 12.4 \\
\hline \multirow[t]{3}{*}{ Gestational age of a child } & extremely preterm(less than 28 weeks) & 96 & 14.8 \\
\hline & Very preterm(between 28 and 32 weeks) & 345 & 53.08 \\
\hline & Late preterm (between 32 and 37 weeks) & 209 & 32.2 \\
\hline \multirow[t]{2}{*}{ Residence area } & Rural & 420 & 64.6 \\
\hline & Urban & 230 & 35.4 \\
\hline \multirow[t]{2}{*}{ Working Status of a child } & yes & 330 & 50.8 \\
\hline & no & 320 & 49.2 \\
\hline \multirow[t]{3}{*}{ Birth order of a child } & first & 165 & 25.4 \\
\hline & $2-4$ & 345 & 50.1 \\
\hline & $>4$ & 140 & 21.5 \\
\hline \multirow[t]{2}{*}{ Admission status } & New & 465 & 71.5 \\
\hline & Readmission & 185 & 28.5 \\
\hline \multirow[t]{3}{*}{ Malnutrition category of a child } & Stunted (height to age) & 425 & 65.4 \\
\hline & Wasted (weight to age) & 120 & 18.5 \\
\hline & Under-weight (height to weight) & 105 & 16.1 \\
\hline \multirow[t]{2}{*}{ Breast feeding history } & yes & 455 & 70.0 \\
\hline & no & 195 & 30.0 \\
\hline \multirow[t]{2}{*}{ Additional disease } & yes & 455 & 70.0 \\
\hline & no & 195 & 30.0 \\
\hline \multirow[t]{3}{*}{ Parent's level of education } & No education & 145 & 22.3 \\
\hline & Primary & 305 & 46.9 \\
\hline & Secondary and above & 200 & 30.8 \\
\hline \multirow[t]{2}{*}{ Mother's stature } & Normal & 95 & 14.6 \\
\hline & Short & 555 & 85.4 \\
\hline \multirow[t]{4}{*}{ Mother's age } & $15-24$ & 153 & 23.5 \\
\hline & $25-34$ & 150 & 23.1 \\
\hline & $35-44$ & 178 & 27.4 \\
\hline & $>=45$ & 169 & 26 \\
\hline \multirow[t]{3}{*}{ Mother's occupation } & Household wife & 153 & 23.5 \\
\hline & Gov't employee & 328 & 50.5 \\
\hline & Private & 169 & 26 \\
\hline \multirow[t]{2}{*}{ Mother's marital status } & Married & 203 & 31.2 \\
\hline & others & 447 & 68.8 \\
\hline \multirow[t]{3}{*}{ HH monthly income(ETB) } & $<500$ & 153 & 23.5 \\
\hline & $500-1000$ & 228 & 35.1 \\
\hline & $>1000$ & 269 & 41.4 \\
\hline \multirow[t]{2}{*}{ Age ranges between children } & $<2$ years & 197 & 69.7 \\
\hline & $=>2$ years & 453 & 30.3 \\
\hline \multirow[t]{3}{*}{ Family size in $\mathrm{HH}$} & $<5$ & 153 & 23.5 \\
\hline & $6-10$ & 228 & 35.1 \\
\hline & $>10$ & 269 & 41.4 \\
\hline \multirow[t]{3}{*}{ No of under-five children in $\mathrm{HH}$} & 1 & 133 & 20.5 \\
\hline & 2 & 248 & 38.2 \\
\hline & $>=3$ & 269 & 41.4 \\
\hline
\end{tabular}


Table 1 (continued)

\begin{tabular}{|c|c|c|c|}
\hline Variables & Category & Frequency & Percentage \\
\hline \multirow[t]{2}{*}{ Type of toilet HH used } & Improved & 352 & 54.2 \\
\hline & traditional & 298 & 45.8 \\
\hline \multirow[t]{2}{*}{ Source of improved drinking water } & yes & 402 & 69.5 \\
\hline & no & 198 & 30.5 \\
\hline \multirow[t]{2}{*}{ Type of cooking fuel } & Moderate & 340 & 52.3 \\
\hline & traditional & 310 & 47.7 \\
\hline \multirow[t]{2}{*}{ Whether there is any other malnutrition in the $\mathrm{HH}$} & yes & 352 & 54.2 \\
\hline & no & 298 & 45.8 \\
\hline \multirow[t]{3}{*}{ Appetite test } & Pass & 54 & 8.3 \\
\hline & fail & 458 & 70.5 \\
\hline & Not recorded & 138 & 21.2 \\
\hline
\end{tabular}

Table 2 Treatment outcomes for under-five children admitted to Therapeutic Feeding Unit

\begin{tabular}{lll}
\hline Variables & Frequency & $\%$ \\
\hline Fail to start in losing edema on 4th day & 330 & 50.8 \\
Presence of edema on the 10th day & 200 & 30.8 \\
Fail to pass to the second phase on the 10th day & 120 & 18.5 \\
$\begin{array}{ll}\text { Fail to gain weight }>5 \text { g per day for three successive } \\
\text { days }\end{array}$ & 254 & 38.5 \\
\hline
\end{tabular}

children coame from families with access of moderate cooking fuel, keeping the other covariates constant.

The average recovery time from SAM for children whose mothers are government employee was longer by $92 \%(\mathrm{HR}=1.95,95 \% \mathrm{CI} ;(1.32,2.35), p$-value $<0.01)$ as compared to those children whose mothers occupation is house hold wife.

Breast feeding and vaccination histories also significantly associated with differences of recovery time of children from SAM. Hence, the average recovery time from SAM for a child who did not get his/her mothers' milk at least for the first six months after born, was increased by $41.9 \%(\mathrm{HR}=1.419,95 \% \mathrm{CI}:(1.13,1.67), p$-value $<.001)$ as compared to children who got mothers milk, keeping the other variables constant. The average recovery time from SAM for children who did not get immunization during their child hood was increased $32.3 \%$ ( $\mathrm{HR}=1.323,95 \%$ CI: $(1.18,1.56), p$-value $=.004)$ as compared to children who got immunization at their child hood. With similar interpretations, the variables like age between children, source of adequate $\mathrm{HH}$ food, size of families and underfive children per families had significant effect on the variable of interest (Refer to Table 4),

In addition to the main effects, important interaction effects were statistically significant for average recovery time of children from SAM. In Table 4, three interaction effects namely age * sex, age*residence area and weight "breast feeding history were statistically significant for the variable of interest (average recovery time).

\section{Interaction effect of age and sex of children}

As it is indicated in Table 4, as age of children increased by one month, the average recovery time of children was decreased by $76.5 \%$ ( $\mathrm{HR}=.235,95 \% \mathrm{CI}:(.109, .342)$, p-value $<.001)$ keeping the other factors constant. However, the decreasing rate of males and females were not the same, hence, as age increased by one month, the decreasing rate of female children was increased by $5.1 \%$ as compared to male children $(\mathrm{HR}=1.051,95 \%$ $\mathrm{CI}=(1.089,1.435), p$-value $<0.001)$.

Interaction effect between age and residence area As it is indicated in Table 4, as age increased by one month, the decreasing rate of urban children was increased by $32.3 \%$ as compared to rural children $(\mathrm{HR}=1.323$, 95\% $\mathrm{CI}=(1.221,1.445), p$-value $=0.002)$.

Interaction effect between weight and breast-milk feeding history As it is indicated in Table 4, as weight increased by one $\mathrm{kg}$, the average recovery time of children decreased by $74.8 \%$ (HR $=.252,95 \%$ CI:(.112, .425), $p$-value $=.002)$ keeping the other factors constant. However, the decreasing rate of children who fed exclussive breast milk at childhood and those who didn't get exclussive breast milk were not the same, hence, as weight increased by one $\mathrm{kg}$, the decreasing rate of children who fed mothers' exclussive breast milk was increased by $58.4 \%$ as compared to those children who did not fed mother's breast milk $(\mathrm{HR}=1.584,95 \% \mathrm{CI}=(1.038$, $1.725)$, $p$-value $=0.003)$. 
Table 3 Log rank test for categorical variables and average recovery time of children from SAM

\begin{tabular}{|c|c|c|c|c|c|c|c|}
\hline \multirow[t]{2}{*}{ Variables } & \multirow[t]{2}{*}{ Categories } & \multirow[t]{2}{*}{ n (\%) } & \multicolumn{3}{|c|}{ Average recovery time } & \multirow[t]{2}{*}{ Chi-square value } & \multirow[t]{2}{*}{$p$-value } \\
\hline & & & Estimate & $95 \% \mathrm{Cl}$ & & & \\
\hline \multirow[t]{2}{*}{ Sex } & Male & $384(59.1)$ & 17.00 & 14.00 & 19.00 & 7.80 & .035 \\
\hline & Female & $266(40.9)$ & 14.00 & 10.56 & 18.00 & & \\
\hline \multirow[t]{2}{*}{ Residence area } & Rural & $420(64.6)$ & 27.00 & 23.00 & 31.54 & 7.78 & .020 \\
\hline & Urban & $230(35.4)$ & 15.00 & 11.50 & 17.00 & & \\
\hline \multirow[t]{3}{*}{ Gestational age } & Ex. preterm & $265(40.8)$ & 18.00 & 14.50 & 22.00 & 8.75 & .032 \\
\hline & Very preterm & $185(28.5)$ & 15.00 & 11.00 & 20.00 & & \\
\hline & Late preterm & $200(30.8$ & 10.15 & 6.54 & 13.50 & & \\
\hline \multirow[t]{3}{*}{ Diagnosis at admission } & Edematous & $425(65.4)$ & 16.00 & 13.00 & 19.00 & 11.54 & .043 \\
\hline & Wasted & $120(18.5)$ & 13.00 & 11.00 & 15.55 & & \\
\hline & Both & 105(16.2) & 18.00 & 15.00 & 20.00 & & \\
\hline \multirow[t]{2}{*}{ Breast feeding history } & yes & $455(70.0)$ & 9.00 & 7.00 & 11.55 & 8.75 & .033 \\
\hline & no & 195(30.0) & 17.00 & 14.00 & 19.56 & & \\
\hline \multirow[t]{2}{*}{ Vaccination history } & yes & $345(53.1)$ & 10.54 & 8.45 & 12.55 & 7.58 & .003 \\
\hline & no & $305(46.9)$ & 14.55 & 12.55 & 16.56 & & \\
\hline \multirow[t]{2}{*}{ Additional disease } & yes & $355(54.6)$ & 16.00 & 13.00 & 18.56 & 9.75 & .038 \\
\hline & no & $295(45.4)$ & 8.50 & 6.00 & 11.00 & & \\
\hline \multirow[t]{2}{*}{ Working status of a child } & yes & 254(39.1) & 15.54 & 11.00 & 17.00 & 8.89 & .024 \\
\hline & no & $396(60.9)$ & 10.50 & 7.50 & 12.55 & & \\
\hline \multirow[t]{3}{*}{ Birth order of a child } & first & $300(46.2)$ & 14.85 & 12.00 & 16.56 & 6.56 & .045 \\
\hline & $2-4$ & $248(38.2)$ & 8.56 & 5.85 & 10.55 & & \\
\hline & $>4$ & $102(15.7)$ & 10.12 & 6.54 & 14.35 & & \\
\hline \multirow[t]{3}{*}{ Mother's Nutritional status } & Under nutrition & $345(53.1)$ & 21.50 & 18.56 & 24.55 & 9.55 & .034 \\
\hline & Normal & 195(30.0) & 16.00 & 13.56 & 18.55 & & \\
\hline & Obese & 110(16.9) & 18.02 & 13.42 & 24.51 & & \\
\hline \multirow[t]{3}{*}{ Parent's education } & No education & 234(36.0) & 15.05 & 12.00 & 21.61 & 8.54 & 0.037 \\
\hline & primary & 253(38.9) & 14.73 & 10.23 & 18.54 & & \\
\hline & Secondary and above & $163(25.1)$ & 16.54 & 12.34 & 20.01 & & \\
\hline \multirow[t]{2}{*}{ Mothers Stature } & Normal & $95(14.6)$ & 14.00 & 12.00 & 17.56 & 12.45 & .035 \\
\hline & Short & $555(85.4)$ & 24.00 & 22.00 & 27.00 & & \\
\hline \multirow[t]{4}{*}{ Mother's age in years } & $15-24$ & $105(16.2)$ & 12.00 & 9.55 & 22.55 & 12.50 & .054 \\
\hline & $25-34$ & $245(37.7)$ & 13.45 & 9.55 & 15.65 & & \\
\hline & $35-44$ & 195(30.0) & 14.24 & 8.92 & 15.06 & & \\
\hline & $>=45$ & $150(23.1)$ & 15.93 & 11.16 & 18.82 & & \\
\hline \multirow[t]{3}{*}{ Mother's occupation } & HH wife & 125(19.2) & 18.05 & 15.00 & 20.55 & 9.55 & .035 \\
\hline & Gov't employee & 200(30.8) & 21.24 & 17.35 & 25.91 & & \\
\hline & Private & $325(50.0)$ & 12.00 & 10.00 & 15.00 & & \\
\hline Mother's marital status & Married & 203(31.2) & 12.54 & 8.00 & 15.55 & 11.54 & .003 \\
\hline & Others & $447(68.8)$ & 17.86 & 13.92 & 20.45 & & \\
\hline HH monthly income(ETB) & $<500$ & 125(19.2) & 18.65 & 15.56 & 20.55 & 9.65 & .004 \\
\hline & $500-1000$ & $96(14.8)$ & 14.56 & 12.00 & 16.56 & & \\
\hline & $>1000$ & $85(13.1)$ & 11.45 & 8.45 & 14.56 & & \\
\hline Age range between children & $<2$ years & 197(30.3) & 15.21 & 18.98 & 25.76 & 8.43 & 0.072 \\
\hline & $>=2$ years & $453(69.7)$ & 10.9 & 13.42 & 23.12 & & \\
\hline Family size of $\mathrm{HH}$ & $<5$ & 187(28.8) & 11.45 & 9.83 & 15.34 & 12.21 & 0.021 \\
\hline & $6-10$ & $379(58.3)$ & 14.02 & 12.34 & 21.45 & & \\
\hline & $>10$ & $84(12.9)$ & 16.58 & 10.83 & 17.51 & & \\
\hline No. of under five children & $<=2$ & $276(42.5)$ & 10.24 & 8.45 & 13.40 & 9.45 & 0.045 \\
\hline & $>2$ & $374(57.5)$ & 14.25 & 10.23 & 18.41 & & \\
\hline
\end{tabular}


Table 3 (continued)

\begin{tabular}{|c|c|c|c|c|c|c|c|}
\hline \multirow[t]{2}{*}{ Variables } & \multirow[t]{2}{*}{ Categories } & \multirow[t]{2}{*}{ n (\%) } & \multicolumn{3}{|c|}{ Average recovery time } & \multirow[t]{2}{*}{ Chi-square value } & \multirow[t]{2}{*}{ p-value } \\
\hline & & & Estimate & $95 \% \mathrm{Cl}$ & & & \\
\hline \multirow[t]{2}{*}{ Use of improved Toilet by $\mathrm{HH}$} & yes & $154(23.7)$ & 12.06 & 11.23 & 18.45 & 10.43 & 0.025 \\
\hline & no & $496(76.3)$ & 15.28 & 10.34 & 17.53 & & \\
\hline \multirow[t]{2}{*}{ Source of adequate $\mathrm{HH}$ food } & yes & $308(47.4)$ & 9.21 & 5.98 & 14.07 & 9.87 & 0.012 \\
\hline & no & $342(52.6)$ & 12.45 & 7.54 & 12.65 & & \\
\hline \multirow[t]{2}{*}{ Source of improved drinking water } & yes & $402(61.8)$ & 9.21 & 5.98 & 14.07 & 10.2 & 0.031 \\
\hline & no & $248(38.2)$ & 12.45 & 7.54 & 12.65 & & \\
\hline \multirow[t]{2}{*}{ Use of moderate cooking fuel } & yes & $247(38.0)$ & 12.54 & 8.48 & 15.04 & 9.57 & 0.032 \\
\hline & no & $403(62.0)$ & 15.98 & 11.65 & 18.34 & & \\
\hline \multirow[t]{2}{*}{ Type of house families live } & Modern & $430(66.2)$ & 10.27 & 8.02 & 14.21 & 10.45 & 0.001 \\
\hline & Traditional & $220(33.8)$ & 13.89 & 10.45 & 15.25 & & \\
\hline \multirow[t]{2}{*}{ Appetite test } & Pass & 229(35.2) & 12.45 & 9.45 & 15.45 & 12.23 & 0.032 \\
\hline & Fail & $250(38.5)$ & 13.62 & 10.12 & 16.51 & & \\
\hline \multicolumn{2}{|l|}{ Average recovery time for all children } & & 21 & 15.23 & 25.77 & & 0.035 \\
\hline
\end{tabular}

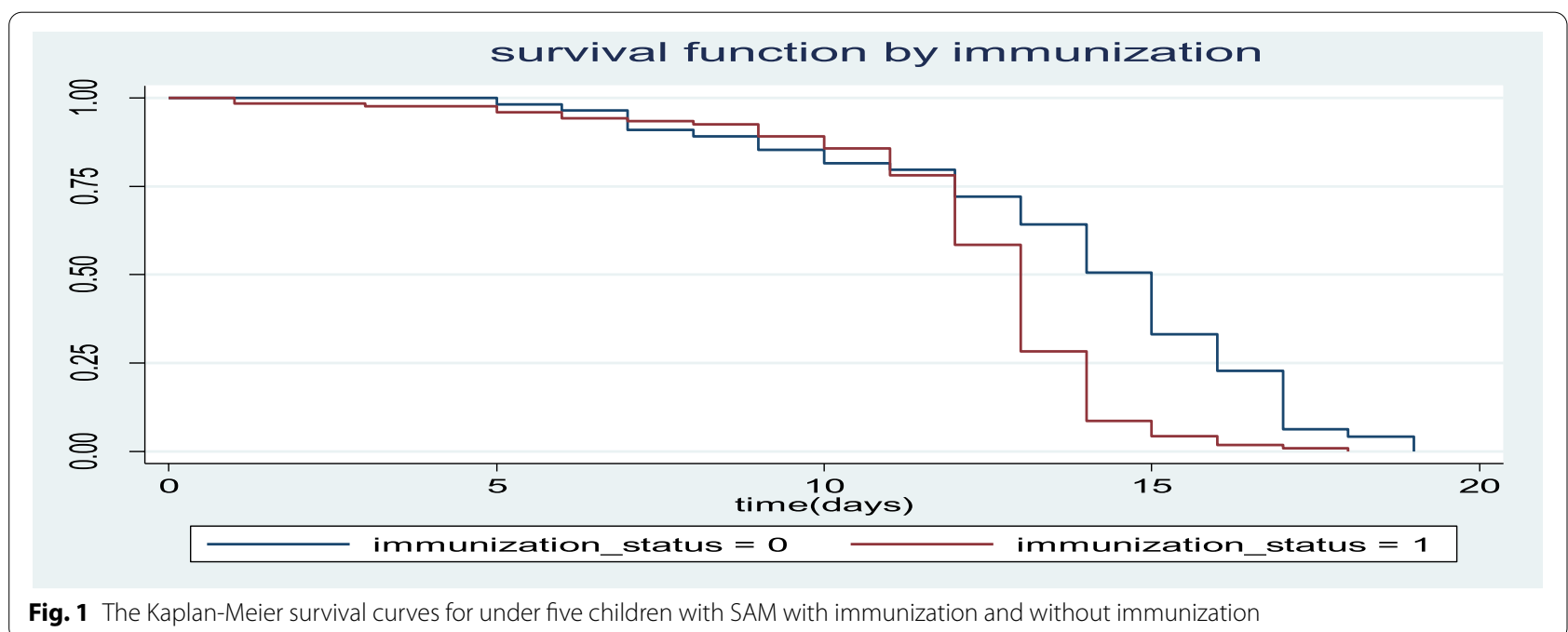

Fig. 1 The Kaplan-Meier survival curves for under five children with SAM with immunization and without immunization

\section{Discussion}

In current investigation, the average recovery time of children from SAM was estimated. The statistical significant variables for difference of recovery time of different groups were also investigated. The assessment was conducted for association between the variable of interest (average recovery time) and predictors. Hence, the average recovery time of children from SAM was found to be 21 days. Eventhough, the value is with in the international standards set $<28$ days, it is long period as compared to other studies in different areas [10].

The finding is contradicted with other retrospective previous studies conducted at Bahir Dar, North west Ethiopia with result 18 days and a research conducted in
Shebedido woreda (southern Ethiopia) which declared that the average recovery time was 19 days $[11,16]$. However, a research conducted in Zambia indicates that the average recovery time from SAM was 13 which is significantly less than a result obtained in current investigation. The potential reason for this difference might be differences in treatment practice, health care surroundings, socio-demographic, economic and related factors in the study areas [11].

Difference in recovery time of children from SAM with additional diseases obtained in this study is consistent with other previous studies. Hence, children with SAM having additional disease needs more recovery time as compared to those children with no disease [14]. 

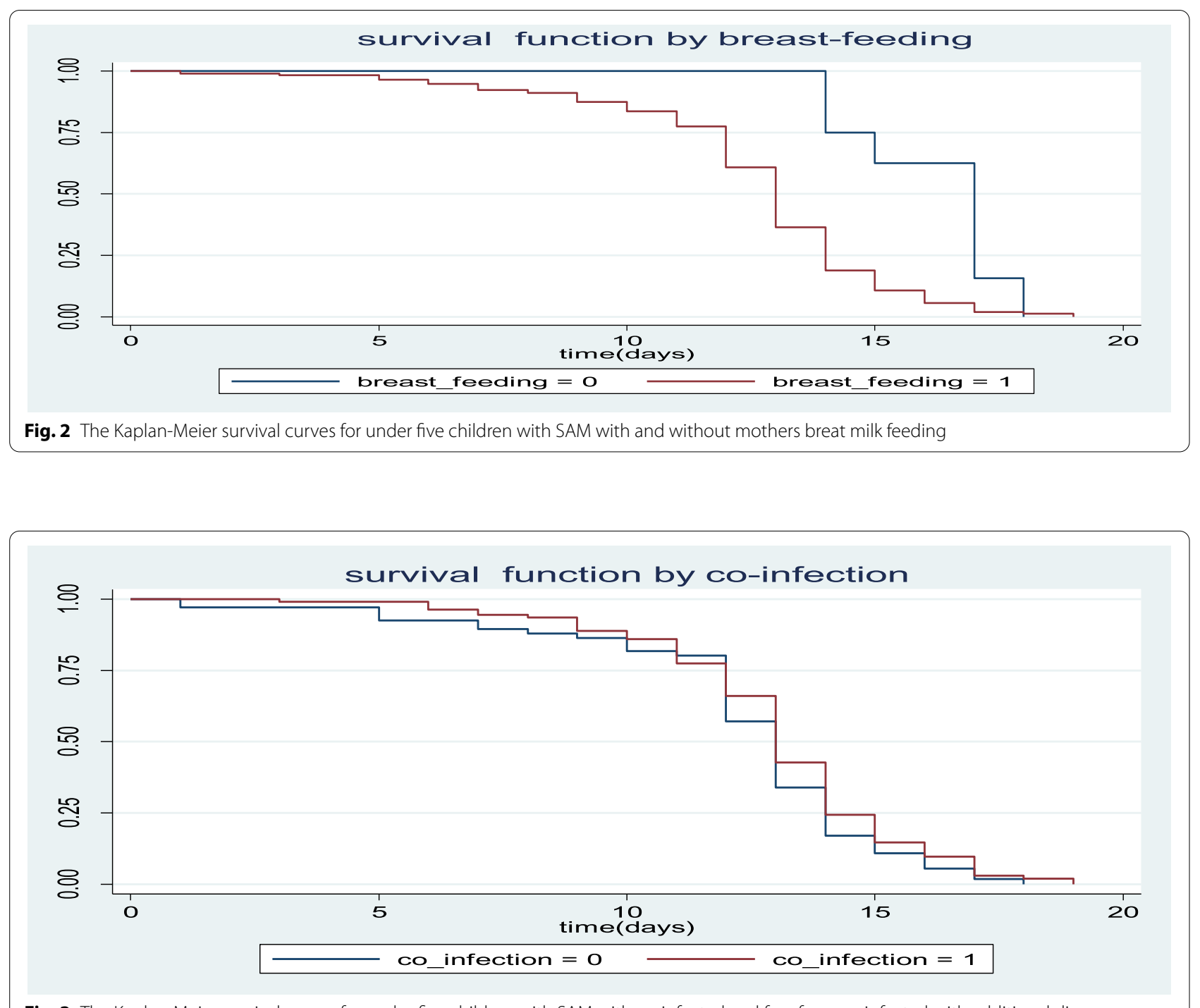

Fig. 3 The Kaplan-Meier survival curves for under-five children with SAM with co-infected and free from co-infected with additional disease

Children admitted in the treatment site because of SAM who come from low income families, families living in traditional house, families who are not using moderate cooking fuel, families who do not have any access of improved drinking water, children born from non-educated parents and children born from his mother with less than 2 years interval do not recover from SAM with short period of time. Such children need some extra time to be recovered from the disease. This finding agrees with a result obtained in previous research [21].

The number of families, especially, number of underfive children per families affect the average recovery time from SAM. Hence, the larger size in number of under-five children, the longer the time it needs for a child to be recovered from SAM. The potential reason for this might be no more attention/care is given for a child because of another under-five children. More family size particularly, unemployed families lead for shortage of adequate $\mathrm{HH}$ food. This finding is also consistent with a result obtained from previous investigations [22, 23].

The result obtained in this research indicates that, children with SAM who had additional disease requires more time to be recovered from SAM as compared to those children who are free from additional disease. This result is contradicted with a research conducted in Burkina Faso [24] which states that additional disease (Anemia) has no negative impact on recovery time and the research agrees with another study conducted in Ethiopia [16]. 
Table 4 Predictors of time to recovery from SAM, Multivariate Cox Proportional hazard Model

\begin{tabular}{|c|c|c|c|c|}
\hline \multirow[t]{2}{*}{ Variables } & \multirow[t]{2}{*}{ Estimate } & \multicolumn{2}{|c|}{ Hazard Rate(HR) } & \multirow[t]{2}{*}{$p$-value } \\
\hline & & Estimate & $95 \% \mathrm{Cl}$ & \\
\hline Intercept & 2.5 & 12.18 & $(8.35,15.54)$ & .002 \\
\hline Age & -1.45 & .24 & $(.11, .34)$ & $<.001$ \\
\hline Weight & -1.38 & .25 & $(.11, .43)$ & .002 \\
\hline \multicolumn{5}{|l|}{ Sex of a child (Ref. $=$ Male) } \\
\hline Female & -1.86 & .16 & $(.13, .45)$ & .005 \\
\hline \multicolumn{5}{|l|}{ Residence area (Ref. $=$ Rural) } \\
\hline Urban & -1.85 & .16 & $(.12, .43)$ & .025 \\
\hline \multicolumn{5}{|l|}{ Gestational age (Ref. $=$ late preterm) } \\
\hline Extermly preterm & .03 & 1.35 & $(1.06,1.67)$ & 0.01 \\
\hline Very preterm & .05 & 1.05 & $(1.02,1.45)$ & .002 \\
\hline \multicolumn{5}{|l|}{ Working status of a child (Ref.=yes) } \\
\hline No & .85 & 2.34 & $(1.12,4.45)$ & .021 \\
\hline \multicolumn{5}{|l|}{ Breast feeding history (Ref. $=$ Yes) } \\
\hline No & .35 & 1.419 & $(1.13,1.67)$ & $<.000$ \\
\hline \multicolumn{5}{|l|}{ Vaccination history(Ref. $=$ Yes) } \\
\hline No & .28 & 1.323 & $(1.18,1.56)$ & .004 \\
\hline \multicolumn{5}{|l|}{ Additional disease history (Ref. $=$ Yes) } \\
\hline No & -0.75 & .47 & $(.13, .61)$ & .002 \\
\hline \multicolumn{5}{|c|}{ Mother's nutritional status(Ref. $=$ under-weight $)$} \\
\hline Normal & -.54 & .58 & $(.13, .85)$ & .003 \\
\hline \multicolumn{5}{|c|}{ Parent's level of education(Ref. $=$ Secondary and above) } \\
\hline No education & 65 & 1.92 & $(1.52,4.58)$ & .012 \\
\hline Primary & .23 & 1.26 & $(1.08,3.46)$ & .023 \\
\hline \multicolumn{5}{|l|}{ Mother's stature $($ Ref. $=$ Normal) } \\
\hline Short & .74 & 2.10 & $(1.13,4.45)$ & .024 \\
\hline \multicolumn{5}{|c|}{ Mother's occupation (Ref.= Household wife) } \\
\hline Gov't employee & .65 & 1.92 & $(1.32,2.35)$ & $<.001$ \\
\hline Private worker & .07 & 1.07 & $(1.01,1.38)$ & .01 \\
\hline \multicolumn{5}{|l|}{ Mother's marital status(Ref. = married) } \\
\hline Others & .87 & 2.39 & $(1.13,3.46)$ & .032 \\
\hline \multicolumn{5}{|c|}{ HH monthly income (Ref.= less than 500) } \\
\hline $500-1000$ & -.09 & .92 & $(.43, .99)$ & .024 \\
\hline$>1000$ & -.93 & .39 & $(0.12,0.57)$ & .01 \\
\hline \multicolumn{5}{|c|}{ Age range between children(Ref. $=<2$ years) } \\
\hline$>2$ years & -2.78 & .062 & $(.132, .452)$ & $<0.061$ \\
\hline \multicolumn{5}{|c|}{ Family size in $\mathrm{HH}($ Ref. $=$ greater than 10$)$} \\
\hline$<5$ & & & $(0.23,0.87)$ & .003 \\
\hline \multirow[t]{2}{*}{$6-10$} & -.45 & .64 & & \\
\hline & -.02 & .98 & $(.45, .99)$ & .021 \\
\hline \multicolumn{5}{|c|}{ No of under-five children in $\mathrm{HH}($ Ref. $=>2)$} \\
\hline$>2$ & -.32 & .72 & $(.35,0.92)$ & .002 \\
\hline \multicolumn{5}{|l|}{ Source of adquate $\mathrm{HH}$ food(Ref.=yes) } \\
\hline No & .02 & 1.02 & $(1.01,1.32)$ & .013 \\
\hline Source of improved drinking water & & & & \\
\hline No & .04 & 1.04 & $(1.01,1.32)$ & .023 \\
\hline Moderate cooking fuel(Ref.=yes) & & & & \\
\hline No & .02 & 1.02 & $(1.001,1.081)$ & .021 \\
\hline Ownership of Livestock(Ref. =yes) & & & & \\
\hline
\end{tabular}


Table 4 (continued)

\begin{tabular}{|c|c|c|c|c|}
\hline \multirow[t]{2}{*}{ Variables } & \multirow[t]{2}{*}{ Estimate } & \multicolumn{2}{|c|}{ Hazard Rate(HR) } & \multirow[t]{2}{*}{ p-value } \\
\hline & & Estimate & $95 \% \mathrm{Cl}$ & \\
\hline No & .43 & 1.53 & $(1.12,1.92)$ & .001 \\
\hline \multicolumn{5}{|c|}{ Appetite test(Ref. $=$ Pass $)$} \\
\hline Fail & .12 & 1.13 & $(1.02,1.45)$ & 0.021 \\
\hline \multicolumn{5}{|c|}{ Age*Sex(Ref.=Male) } \\
\hline Female & .05 & 1.051 & $(1.089,1.435)$ & $<.001$ \\
\hline \multicolumn{5}{|c|}{ Age ${ }^{*}$ Residence area(Ref. $=$ Rural) } \\
\hline Urban & .28 & 1.323 & $(1.221,1.445)$ & .002 \\
\hline \multicolumn{5}{|c|}{ Weight ${ }^{*}$ mother; breast milk feeding $($ Ref. $=$ Yes $)$} \\
\hline No & .46 & 1.584 & $(1.038,1.725)$ & 0.003 \\
\hline
\end{tabular}

The potential reason for this difference might be health care surroundings and other socio-economic determinants among children in the study areas.

Conclusion The average recovery time of children from SAM in the study area was 21 days, which is really long period of time compared with researches conducted in any other areas and different groups with different characteristics. Weight of a child at birth, gestational age of a child, working status of a child at admission, birth order of a child, mother's BMI, parent's level of education, mother's stature, mother's occupation, mother's age, mother's marital status, mother's nutritional status, house hold income in ETB, family size in $\mathrm{HH}$, number of under-five children, the type of toilet used in $\mathrm{HH}$, the type of house families live, source of improved drinking water, type of cooking fuel, sex of a child, residence area, malnutrition type, age of a child at admission and weight of a child were identified as predictors for the variation of average recovery time from SAM.

As recommendation, the area, where current investigation was conducted needs special intervention for children to be free from stunting, wasting and under-weighting. The children faced with lack of balanced diet and this further leads to be affected by the different diseases.

Awareness should be created to the community to feed mothers' breast milk, to use moderate cooking fuel, to use improved drinking water, to have few numbers of children per family (family planning) and vaccinate their children at child hood and vaccination program should be continued with large coverage including rural areas. Attention should be given for children with additional disease and a child who come from families who have more children with malnutrition status. More attention should be given for those children who did not start to reduce their edema during their follow up time and for those children who can't pass to phase 2 during their follow up time.

This study has both theoretical and methodological contributions. The interaction effect between covariates can be considered as theoretical contribution. According to the analysis given in current study, suggestions are given to improve the average recovery time of children from SAM in study area and enhance the equality in variable of interests between different groups (male and female, urban and rural, children with families of different level of education, children with families of different economic and living standared). Hence, from a policy point of view, the main findings of current study suggest that a special attention should be given for children who have londer waiting time to be recovered from SAM which is an indication of practical contribution.

\section{Abbreviations}

SAM : Severe Acute Malnutrition; HIV: Human Immune deficiency virus; AHR: Adjusted Hazarded Ratio; Cl: Confidence interval; RUTF: Ready to use therapeutic food; MUAC: Mid-upper-arm circumstance; SPSS : statistical packages for social science.

\section{Acknowledgements}

Dubti Referral Hospital and all health staffs are gratefully acknowledged for the data they supplied for our health research. The authors also aknologed Prof. Abiy Yigzaw for his high contribution in languge edition.

\section{Authors' contributions}

AT developed data collection format, supervised the data collection process, and analyzed and interpreted the data and first draft of the manuscript. DB participated in developing data collection format and data analysis and critically read the manuscript and gave constructive comments for betterment of the manuscript. All authors have contributed to manuscript preparation. The author(s) read and approved the final manuscript. 


\section{Availability of data and materials}

The data used for current investigation is availiable under corresponding author.

\section{Declarations}

\section{Ethical consideration and consent to participation}

Ethical clearance certificate had been obtained from Bahir Dar University Ethics Committee, Ethiopia, with Ref $\neq$ RCS/1412/2008. We can attach the ethical clearance certificate upon request. The committee, established under Bahir Dar University waved consent to participants to use the data for this research. The work reported in the manuscript was performed according to the national and international institutional rules concerning animal experiment, clinical studies and biodiversity rights. Hence, the clinical data collected by the health staff for medication purpose, was secondary data for current study, the informed consent to participant was waived by the ethics committee of Bahir Dar University.

\section{Consent to publication}

This manuscript is not published in any other journals or not under consideration by any other journals.

\section{Competing interests}

As no individual or institution funded this research, there was no conflict of financial and non-financial interest between authors or between authors and institutions.

Received: 16 May 2021 Accepted: 19 November 2021

Published online: 10 December 2021

\section{References}

1. Black RE, et al. Maternal and child undernutrition and overweight in lowincome and middle-income countries. Lancet. 2013;382(9890):427-51.

2. Griggs D, et al. Policy: sustainable development goals for people and planet. Nature. 2013;495(7441):305.

3. Le Blanc D. Towards integration at last? The sustainable development goals as a network of targets. Sustain Dev. 2015;23(3):176-87.

4. Sanchez PA, Swaminathan MS. Cutting world hunger in half. Science. 2005;307(5708):357-9.

5. Gebremichael DY. Predictors of nutritional recovery time and survival status among children with severe acute malnutrition who have been managed in therapeutic feeding centers, southern Ethiopia: retrospective cohort study. BMC Public Health. 2015;15(1):1267.

6. Keesstra SD, et al. The significance of soils and soil science towards realization of the United Nations sustainable development goals. Soil. 2016;2(2):111-28.

7. Tangcharoensathien V, Mills A, Palu T. Accelerating health equity: the key role of universal health coverage in the sustainable development goals. BMC Med. 2015;13(1):101.

8. Buse K, Hawkes S. Health in the sustainable development goals: ready for a paradigm shift? Glob Health. 2015;11(1):13.

9. Rasul G. Managing the food, water, and energy nexus for achieving the sustainable development goals in South Asia. Environmental Development. 2016;18:14-25.

10. Organization, W.H., Pocket book of hospital care for children: guidelines for the management of common childhood illnesses. 2013: World Health Organization.

11. Mengesha MM, et al. Treatment outcome and factors affecting time to recovery in children with severe acute malnutrition treated at outpatient therapeutic care program. Glob Health Action. 2016;9(1):30704.

12. Maleta K, Amadi B. Community-based management of acute malnutrition (CMAM) in sub-Saharan Africa: case studies from Ghana, Malawi, and Zambia. Food Nutr Bull. 2014;35(2_suppl1):S34-8.

13. Tadesse $\mathrm{E}$, Ekström E-C, Berhane $\mathrm{Y}$. Challenges in implementing the integrated community-based outpatient therapeutic program for severely malnourished children in rural southern Ethiopia. Nutrients. 2016;8(5):251.
14. Legesse $H$, et al. National scale-up of integrated community case management in rural Ethiopia: implementation and early lessons learned. Ethiop Med J. 2014;52(Suppl 3):15-26.

15. Mokgatle M, Demisse B. Community-based management programme for treatment of acute child malnutrition using the out-patient therapeutic treatment approach in Dhas district of Ethiopia: public health intervention for maternal and child health. African Journal for Physical Health Education, Recreation and Dance. 2015;21(Supplement 2):39-49.

16. Asres DT, Prasad RP, Ayele TA. Recovery time and associated factors of severe acute malnutrition among children in Bahir Dar city, Northwest Ethiopia: an institution based retrospective cohort study. BMC Nutrition. 2018;4(1):17.

17. Organization, W.H., Global Nutrition Targets 2025: Low birth weight policy brief. 2014.

18. Organization, W.H., Global nutrition targets 2025: wasting policy brief. 2014.

19. Organization, W.H., Global report on diabetes. 2016: World Health Organization.

20. Johnson, C.L., et al., National health and nutrition examination survey: sample design, 2011-2014. 2014.

21. Sellen, D., et al., Strengthening Family Planning with Community-based Nutrition Interventions in Ethiopia: A Qualitative Study. 2012.

22. Wu, M., Making Nutrition Policy Central to Development Understanding the Political and Institutional Conditions for Policy Change. 2009.

23. Black RE, et al. Global, regional, and national causes of child mortality in 2008: a systematic analysis. Lancet. 2010;375(9730):1969-87.

24. Savadogo LGB, et al. Impact of anemia on mortality and nutritional recovery among hospitalized severely malnourished children in Burkina Faso. Open journal of pediatrics. 2014;4(01):115.

\section{Publisher's Note}

Springer Nature remains neutral with regard to jurisdictional claims in published maps and institutional affiliations.

Ready to submit your research? Choose BMC and benefit from:

- fast, convenient online submission

- thorough peer review by experienced researchers in your field

- rapid publication on acceptance

- support for research data, including large and complex data types

- gold Open Access which fosters wider collaboration and increased citations

- maximum visibility for your research: over 100M website views per year

At BMC, research is always in progress.

Learn more biomedcentral.com/submissions 